\title{
Tibet's Invisible Languages and China's Language Endangerment Crisis: Lessons from the Gochang Language of Western Sichuan
}

\author{
Gerald Roche* and Yudru Tsomu ${ }^{\dagger}$ \\ This is the accepted manuscript for Roche, Gerald and Yudru Tsomu. 2018. Tibet's Invisible \\ Languages and China's Language Endangerment Crisis: Lessons from the Gochang \\ Language of Wester Sichuan. China Quarterly. 233:186-210.
}

https://doi.org/10.1017/S0305741018000012

\begin{abstract}
China is facing a language endangerment crisis, with half of its languages decreasing in number of speakers. This article contributes to the understanding of language endangerment in China with a case study of the Gochang language, which is spoken by about 10,000 Tibetans in western Sichuan. We describe Gochang as an "invisible" language - one that is overlooked by the state's ethnic and linguistic policies and thus is more vulnerable to the social transformations wrought by statist development. Using UNESCO's language vitality and endangerment framework to assess the endangerment of Gochang, we conclude that the language is "definitely endangered." Our comparison of Gochang with other "invisible" languages in China shows that most are in a similar predicament, suggesting that China's language endangerment crisis is likely to continue unless these languages receive formal recognition or local governments take advantage of ambiguities in the policy framework to support them. The social impacts of a continuing, deepening language endangerment crisis in China are as yet unknown.
\end{abstract}

Keywords: Tibet; China; language endangerment; language policy

China is facing a language endangerment crisis, with approximately half of its languages endangere ${ }^{1}$ - far above the 20 per cent background rate for Asia as a whole. ${ }^{2}$ Numerous studies on individual languages paint a similarly grim picture of widespread endangerment. ${ }^{3}$ And although this crisis impacts both the Han majority and ethnic minorities, the latter seem particularly affected: in 2000, 10 out of China's 55 minority nationalities maintained their minority language at a rate below half of their official population, evidence of massive language loss. ${ }^{4}$

$\mathrm{Xu}$ Shixuan argues that this high rate of endangerment is a result of economic globalization, urbanization, the marginalization of minority languages, and pressure from dominant languages. ${ }^{5}$ These "dominant" languages include not only the national language (putonghua 普通话) but also regionally dominant varieties of "Chinese" as well as ethnic minority languages (including Mongolian, Lahu 拉祜语, Nuosu Yi 诺 苏彞语, and Lisu 傈僳语). The dynamics underlying language endangerment in

\footnotetext{
*Asia Institute, University of Melbourne. Email: g.roche@unimelb.edu.au (corresponding author).

${ }^{\dagger}$ Center for Tibetan Studies, Sichuan University.
} 
China are therefore more complex than universal assimilation to putonghua. In this article, we contribute to our expanding understanding of these complexities with a case study of the Gochang language (guiqiong 贵琼语), spoken by Tibetans in Sichuan province.

Any study of language endangerment in China must be considered in light of our evolving understanding of the country's linguistic diversity. David Bradley notes that, "China is one of the last places on earth where there are large numbers of unreported and undescribed languages." 7 Tibet provides a case in point. ${ }^{8}$ An emerging consensus among linguists is that it is "no longer viable" to consider "Tibetan" as a single language; 9 instead, it constitutes a family containing multiple languages. ${ }^{10}$ In addition to these "Tibetic" languages, Tibetans in China also speak some 26 non-Tibetic languages. ${ }^{11}$ Furthermore, in addition to Tibetans, Tibet is home to at least 14 other formally recognized ethnic groups (minzu 民族), who speak 33 different languages. Taken together, the non-Tibetic languages spoken in Tibet by Tibetans and members of other ethnic groups are referred to as Tibet's minority languages. ${ }^{12}$ The language we focus on, Gochang, is one such language. We refer to it here as an "invisible" language, since it is unrecognized by the state and hence is invisible to the official gaze which determines the allocation of material and moral resources to language communities. Invisible languages spoken by Tibetans, such as Gochang, make up nearly half (26 out of 60) of Tibet's minority languages.

Research on endangerment among Tibet's minority languages is an emerging field. A preliminary discussion of the topic concluded that while language endangerment among Tibet's minority languages appears widespread, "[much] remains to be learned about the shared, and different, fates" of these languages. ${ }^{13}$ Gerald Roche and Hiroyuki Suzuki, combining data from Lewis, Simons and Fennig with their own sociolinguistic typology, estimate that approximately two-thirds of Tibet's minority languages are endangered. ${ }^{14}$ Case studies of individual languages also suggest that endangerment is widespread. Mátyás Balogh reports that Henan Oirat (Qinghai) is "critically endangered," while Tunzhi describes Rta'u (Sichuan) as "clearly endangered." 15 John van Way and Bkrashis Bzangpo claim that Nyagrong Minyag (Sichuan) is "hanging from a precarious ledge," with many speakers shifting to the local Tibetic variety, a situation also described by Robert Fried in reference to the Manegacha language (Qinghai). ${ }^{16}$ Katia Chirkova reports that the Lizu language (Sichuan) is endangered "due to the decreasing number of fluent speakers and the ongoing shift towards Chinese,"17 and that the Duoxu 多续 language (Sichuan) is "terminally endangered." "The Namuyi language (Sichuan) has been described as "very much an endangered language." "These studies are suggestive of widespread endangerment among Tibet's minority languages. Here, we add to this picture with a case study of the Gochang language of western Sichuan.

Gochang is typically referred to as guiqiong, a pinyin 拼音 rendering of the local pronunciation of the language's name. ${ }^{20}$ It is spoken primarily in the valley and tributaries of the Dadu River 大渡河 ${ }^{21}$ in north-eastern Kangding 康定 ${ }^{22}$ municipality in Kardze Tibetan Autonomous Prefecture. ${ }^{23}$ The area where the language is spoken was, until 1949, known as Gotang, ${ }^{24}$ and was ruled over by a local hereditary king. ${ }^{25}$ Gochang is an oral language, spoken by about 10,000 people, and is classified as a 
Qiangic language, and thus only distantly related to the Tibetic languages. Most Gochang speakers are officially classified as Tibetans (zangzu 藏族). This study highlights salient features of the endangerment of Gochang, thus providing important insights into the complex ways in which national language and ethnic policies interact with statist development to produce language endangerment, particularly for China's "invisible" languages. ${ }^{26}$

\section{Language Endangerment and Vitality}

Our study of Gochang adopts a "language endangerment" approach, a framework that emerged in the 1990s, in recognition of a global language endangerment crisis. ${ }^{27}$ This approach quickly spread to China. ${ }^{28}$ One of the central methods of the language endangerment approach has been the systematic assessment of language endangerment through the concept of language vitality. Language vitality models provide rubrics for assessing language endangerment and sustainability within the context of a particular linguistic, social, political and cultural environment. ${ }^{29}$

We adopt the UNESCO Language Endangerment and Vitality Framework in our discussion. ${ }^{30}$ This model assesses vitality according to nine factors: intergenerational language transmission; absolute number of speakers; proportion of speakers within the total population; trends in existing language domains; response to new domains and media; materials for language education and literacy; government and institutional language attitudes and policies, including official status and use; community members' attitude towards their own language; and urgency for documentation. For each category - except number of speakers - UNESCO ranks results on a scale from 0 to 5 .

Our description is based on both primary and secondary literature, as well as the second author's status as a Gochang speaker. She is intimately familiar with the area and has a broad network of relatives, friends and associates throughout Gotang with whom she consulted. We also visited Gotang in January and July of 2016 and visited most Gochang-speaking villages. The significance of our contribution lies in being bringing our Tibetological, historical and anthropological perspectives to this topic, which has so far only been examined by linguists working primarily with Chinese literature.

\section{Language Diversity in Sichuan's Tibetan Regions}

Linguistic diversity in Tibet generally increases with population density, meaning that it increases from west to east across the Tibetan Plateau. The vast majority of minority languages spoken by Tibetans in China are spoken only in Sichuan province. ${ }^{31}$ These indigenous languages are spoken in Ngawa ${ }^{32}$ Tibetan and Qiang 㒸 Autonomous Prefecture, Kardze Tibetan Autonomous Prefecture and several adjacent counties to the east of this area where Tibetans live, as well as within Liangshan 凉山 Yi Autonomous Prefecture. Table 1 lists these languages with reference to literature on each.

Typesetter: please insert Table 1 about here

Knowledge of western Sichuan's linguistic diversity stretches back to the 18th century, when vocabularies for Duoxu, Lizu, Baima, and Situ rGyalrong were 
assembled. ${ }^{33}$ Studies by Westerners date back to the mid-19th century, with wordlists of various languages published between 1853 and $1936 .{ }^{34}$ Brief, and generally unflattering, mentions of the region's languages also appeared in the reports of missionaries and others. ${ }^{35}$ Yudru Tsomu has documented the intensifying production of ethnographic knowledge about Sichuan's Tibetan regions after 1911 as part of the Republican effort to incorporate the region. ${ }^{36}$ This includes Jiang Wuji's account of Gotang, which we draw on. ${ }^{37}$

A long hiatus in publishing on the languages of western Sichuan followed 1949. Although some linguistic research was conducted as part of the ethnic identification project between 1953 and 1959, very little was published in the 1950s and 1960s. ${ }^{38}$ During the Cultural Revolution, work on minority languages ceased, but then gradually resumed after 1978, and flourished in the $1980 \mathrm{~s} .{ }^{39}$ An important milestone during this period was Sun Hongkai's study published in 1983, and republished in English in 1990 under the title "Languages of the ethnic corridor of western Sichuan"; this article introduced international linguistics audiences to many of western Sichuan's languages for the first time. ${ }^{40}$

Research on the languages of the region has steadily increased since then, and has intensified in the 21 st century. It is only since 2005 that many of the region's languages have been described in detail for the first time. Increasing interest in these languages can also be seen in the convening of a series of international conferences, beginning in 2008, on the "Sino-Tibetan Languages of Western Sichuan." Much of the work being done on these languages remains descriptive, although some sociolinguistic research is now starting to emerge. ${ }^{41}$

\section{The Linguistic Vitality of Gochang}

\section{Intergenerational language transmission}

Intergenerational language transmission is widely regarded as the most important criterion in determining language vitality. ${ }^{42} \mathrm{Jiang} \mathrm{Li}$ and Song Lingli both suggest that the intergenerational transmission of Gochang has ceased, while Yuan Li, Jin Ming and Cao Rong together report that less than 10 per cent of "young people" can speak Gochang. ${ }^{43}$ Our observations suggest that intergenerational transmission was interrupted relatively recently. For reasons we explore below, most children aged around ten and below are now dominant in Sichuan Chinese, while those above ten are bilingual in Sichuan Chinese and Gochang. In light of this, we classify the language as "definitively endangered" - "the language is used mostly by the parental generation and up." 44 Gochang is thus joining a number of other languages in China that are being replaced by local varieties of Chinese. ${ }^{45}$ Figure 1 highlights the extent of language shift among China's ethnic minorities.

Typesetter: please insert Figure 1 about here, with the following title and source Figure 1: Language Maintenance among Ethnic Minorities in China Source:

Data from Zhou, Minglang 2012. 


\section{Absolute number of speakers}

In consultation with written and oral sources, Jiang estimates that there are 9,677 Gochang speakers, and an additional almost 3,000 "listeners" with passive competence in the language, giving a total of 12,677 people who are able to understand Gochang. ${ }^{46}$ Jiang also notes that "over 1,000" Han Chinese also speak Gochang, so the total of speakers should therefore perhaps be $10,677 .{ }^{47}$ This figure can be contrasted with Sun's estimate of 7,000 speakers, Huang Bufan's of 6,000, and Song's of $3,000 .{ }^{48}$ Within China, over a third of the languages listed in the 18th edition of Ethnologue (104 languages, or 35 per cent) have populations of 10,000 or fewer speakers.

\section{Proportion of speakers within the total population}

The third UNESCO criterion refers to the relative proportion of people who speak the language within a total population, wherein that total population "may refer to the ethnic, religious, regional, or national group with which the speaker community identifies." ${ }^{49}$ Here, we offer three estimates of the proportion of speakers vis-à-vis different definitions of the "reference population," based on local, ethnic and national populations.

The first estimate focuses on the former territories of the Gotang King, roughly corresponding to the area for which Jiang collected population data. She states that there are a total of 16,359 Tibetans in the area, and among these, 9,677 speak Gochang. Therefore, just under 60 per cent (59.15 per cent) of Tibetans in the former Gotang territory speak Gochang. This, however, excludes the non-Tibetan population of the region, which is significant, primarily owing to the urban population of Guza town, which $\mathrm{Li} \mathrm{Na}$ lists as $50,000 .^{50}$

Since the 1980s, Guza has grown from a collection of eight villages and a handful of administrative offices surrounded by fields to a dense cluster of multistorey buildings.

Typesetter: please insert Figure 2 about here, with the following title and source Figure 2: Guza Town

Source:

Photograph by Gerald Roche.

Rapid growth was instigated by economic reform and the implementation of the household responsibility system. Simultaneously, several technical schools (zhongzhuan 中专) were opened. In the late 1980s, the demographic balance between locals and migrants tipped, minoritizing the Gochang-speakers in Guza. Urban growth intensified owing to an artisanal gold-mining boom from the late 1990s to mid-2000s. Local tertiary education institutes were upgraded, consolidated and expanded from 2004 and 2013, leading to a growth in staff, student populations and service-provider populations. In 2011, around 500 Gochang-speaking households 
were resettled following the damming of the Dadu River. ${ }^{51}$ In addition to permanent resettlement, rotating migration is also common. Many adults spend most of the year outside the village, undertaking migrant labour in Guza or other places, leading to rural abandonment. In Weishe 为舍 village, only 12 people out of approximately 330 residents live in the village year-round, while in Yazi 芽子 village, only seven or eight of the 20 houses were thought to be inhabited year-round. This seasonal migration by villagers is not only incentivized by the financial gains to be had from migrant labour, but also facilitated by "grain-for-green" policies, which, since their implementation in 2000 , have divorced people from their rural subsistence base. ${ }^{52}$

Typesetter: please insert Figure 3 about here with the following title and source Figure 3: Resettlement Communities in Guza

Source:

Photographs by Gerald Roche.

A related issue has been Han immigration to Gotang. Although dating back to the late Qing, Han immigration has intensified since the 1980s. Permanent resettlement of Gochang-speakers to Guza, rural abandonment, rotating migration, and Han immigration have all resulted in the demographic minoritization of Gochang speakers in Gotang. ${ }^{53}$

Within the ethnic context, Gochang speakers constitute only 0.16 per cent of the total Tibetan population. ${ }^{54}$ In total, Tibetans who speak a minority language constitute 4 per cent of the total Tibetan population. ${ }^{55}$ Even if we take the entire linguistic minority population of Tibetans as a referent population, Gochang speakers only constitute approximately 4.5 per cent.

Finally, within the People's Republic of China (PRC), Gochang speakers constitute a mere 0.00076 per cent of the total. However, this should be noted in light of the fact that about one-third of China's languages have populations similar to or smaller than that of Gochang.

Looking at these three demographic frames - local, ethnic and national - the proportion of Gochang speakers within the total population can be thought of as somewhere between "severely endangered" (a minority speak the language) and "critically endangered" (very few speak the language). Urbanization and immigration have been key drivers of the demographic minoritization of Gochang speakers, similar to many other endangered languages throughout China. ${ }^{56}$

\section{Trends in existing language domains}

A "domain" is a sociolinguistic context in which a language is used - the "major institutions in society: e.g. the family, the work sphere, education, religion, entertainment and the mass media, the political party, the government, etc." 57 UNESCO's use of domains in its language vitality framework is based on Joshua Fishman's hypothesis that in order for a language to be vital, it must have "domain specificity", i.e. have certain domains where it is used exclusively. ${ }^{58}$ UNESCO classifies domains into "new" and "existing" without providing operational 
definitions of these terms, and so we divide "new" from "existing" with 1949 and the founding of the PRC as a watershed.

Regarding the agricultural domain, Jiang points out that Gochang has a rich agricultural vocabulary and "not only contains original names for grains, crops and fruit trees, [but] also contains distinctive ways of sowing, detailed names of various parts of a tilled field, and specified names of various parts of earliest tilling device." Otherwise, Tibetan appears to dominate domains beyond subsistence and domestic tasks.

Oral traditions constituted a significant aspect of popular culture in the era before mass media. In Gotang, oral traditions were overwhelmingly in a local pronunciation of literary Tibetan. Songs were mostly sung in Tibetan, and although locals understood the general meaning, they could not understand individual lines of text or isolate specific words. This follows a pattern common among Tibet's linguistic minorities, who often spoke one language but sung in another. ${ }^{60}$ Speeches given on such occasions as weddings were also in Tibetan, and again, this has parallels elsewhere in Tibet. One important oral tradition - the recitation of the Epic of King Gesar - consisted of both spoken and sung sections; spoken portions were in Gochang while sung portions were in Tibetan. Completing the spectrum of oral traditions, we find folktales which, although told in Gochang, were typically based on Tibetan templates, such as the Story of Salt and Tea and The Frog Rider. ${ }^{61}$

Religion is another important domain in Gotang. ${ }^{62}$ The three main religious practitioners in the region - loumu (Buddhist monks), gongma (tantric specialists) and amcho (lay Buddhist specialists) - all make use of Tibetan language scriptures. The monks, moreover, reinforce this close relation between Tibetan Buddhism and the written Tibetan language by offering free Tibetan literacy classes to local children during school holidays, as well as maintaining libraries of Tibetan-language books at the two monasteries. The dominance of Tibetan script in this domain not only conferred upon it a specific role in the local language ecology but also conferred prestige, rooted in sacred power, upon the language.

Jiang provides useful observations on other domains in Gotang prior to 1949. ${ }^{63}$ There were two primary schools in the area, which enrolled a total of 28 students and taught in Chinese. Meanwhile, legal appeals were made to village headmen, presumably in Gochang, but could be escalated until they reached the local government, at which level Chinese would have been used. Jiang also states that the Gotang King and some local headmen were fluent in Chinese and could also read it, whereas commoners in Gotang, other than in a few communities along the river, could not speak Chinese.

Based on the above description, the situation regarding existing domains can be described as one of "multilingual parity," "whereby the non-dominant language is used in informal and home contexts and the dominant language is used in official and public contexts." 64 The "dominant" language in this case was Tibetan, but Chinese also played a limited role. Gochang was used in domestic and subsistence contexts, and Tibetan was used in most formal contexts, although elites used Chinese. The intense contact with Tibetan is attested to, in part, by the existence of numerous Tibetan loanwords in Gochang. ${ }^{65}$ The social bilingualism in Gotang was a classic 
example of diglossia, where a local vernacular existed alongside "a very divergent, highly codified ... superposed variety, the vehicle of a large and respected body of written literature, either of an earlier period or in another speech community, which is learned largely by formal education and is used for most written and formal spoken purposes but is not used by any section of the community for ordinary conversation." ${ }^{, 66}$ Similar diglossic situations seem to have pertained for many of Tibet's minority languages ${ }^{67}$ more broadly, the great scriptural traditions of China likely bound the vast majority of the country's "invisible" languages into some form of diglossic relation with a literary language and, possibly, associated oral traditions.

\section{Response to new domains and media}

UNESCO states that, "If the communities do not meet the challenges of modernity with their language, it becomes increasingly irrelevant and stigmatized.." ${ }^{, 8}$ As new domains - for example, mass media, state bureaucracy, formal education - appear, they are typically filled by state-sponsored dominant languages, resulting in minority languages being "restricted to use in the home and perhaps among friends." ${ }^{69}$ This marginalization, in turn, frequently causes speakers of minority languages to feel that their language is "useless," leading to its abandonment. ${ }^{70}$ Furthermore, the proliferation of new domains enforces notions of the language's uselessness when it becomes apparent that the language "is increasingly unable to talk about all the new things and ideas that are being introduced from the modern world." ${ }^{71}$ In the discussion that follows, we see that Gochang has, indeed, been excluded from most new domains in favour of Chinese, both the standard and the local vernacular forms.

We have already seen above how the Republican period witnessed attempts to establish Chinese-language state institutions, including schools and legal services, in Gotang. However, these never had a strong impact, and it was not until after the region was "liberated" in 1950, and particularly after June 1951 when local military resistance was definitively quashed, that the national government came to exert significant direct influence in the area. Today, the main government offices of the Gotang region are located in Guza town, with smaller offices in townships and some outreach services such as medical clinics in villages. Although these offices conspicuously display Tibetan script ${ }^{72}$ the language used within them is exclusively Chinese. Therefore, locals must use spoken and written Chinese for a host of bureaucratic tasks such as negotiating tax payments, obtaining a construction permit or business licence, requesting permission for a change in land usage or residential registration, receiving student financial aid or poverty alleviation subsidies, registering newborn children or deaths, or applying for medical rebates. State-owned or operated businesses, such as the postal service and banks, also use Chinese. In all these official contexts, even if both interlocutors know Gochang, some form of Chinese is used. ${ }^{73}$

Typesetter: Please insert Figure 4 about here with the following title and source. Figure 4: Tibetan and Chinese Script Used on Signs for Government Offices in Guza 


\section{Source:}

Photograph by Gerald Roche.

Meanwhile, all local educational services are now located in Guza; the closure of village primary schools began in the early 21 st century. Guza is home to two kindergartens (one private, one public), a primary school, a junior middle school, ${ }^{74}$ and two tertiary education institutions - Sichuan Minzu College (Sichuan minzu xueyuan 四川民族学院) and a medical college (Ganzi zangzu zizhizhou weisheng xuexiao 甘孜藏族自治州卫生学校). Local participation in formal schooling increased sharply after compulsory education policies began to be enforced in 20072008, requiring all students to complete nine years of education, from primary to junior middle school. And although kindergarten is not compulsory, most locals feel that it is required in order for children to be competitively placed in their later schooling. The language of instruction at all of these institutions is Chinese - no Gochang is used. ${ }^{75}$ Students can board at school from grade three upwards, which increases their exposure to Chinese.

Finally, in regard to media, locals have access to television in both putonghua and Tibetan (Amdo, Khams, and U-Tsang varieties of Tibetan). ${ }^{76}$ Elders, who typically understand neither Chinese nor Tibetan well, prefer to watch Tibetan stations, as song and dance performances predominate on these channels. Meanwhile, adults and youths, who understand Chinese but not Tibetan, prefer to watch Chinese language stations. Radio is also available in both languages, but Chinese predominates. Popular music is in both Chinese and Tibetan, but Korean and English songs can also be heard locally. In terms of print media, locally available newspapers and books are primarily in Chinese; only one bookstore in Guza sells Tibetan books. The only form of media where Gochang is used is social media, particularly the popular messaging service WeChat, which enables locals to exchange voice messages in Gochang.

In summary, then, the last 60 years have seen the appearance of numerous new domains in Gotang. Some of the new domains are in direct competition with existing ones. New media forms, for example, are replacing oral traditions. This therefore brings Tibetan and Chinese, as local prestige languages, into direct competition. On the other hand, even when new domains are not in direct competition with existing ones, they impact Gochang's vitality by creating institutions for social prestige and mobility that are associated exclusively with the dominant language. In this context, we rate Gochang as the lowest possible rank for this criterion, "inactive," meaning that, "The language is not used in any new domains." ${ }^{, 77}$ In this respect, Gochang is in a similar predicament to all of China's "invisible" languages, ${ }^{78}$ as well as most of the smaller, formally recognized languages. ${ }^{79}$

\section{Materials for language education and literacy}

In introducing this criterion, the UNESCO guidelines note that "Education in the language is essential for language vitality." 80 And although they concede, along with Lenore Grenoble and Lindsay Whaley that "the relationship between literacy and 
language vitality is a rather complex matter," the UNESCO guidelines nonetheless conclude that literacy is positively correlated with vitality. ${ }^{81}$

Gochang is presently unwritten and so there are no materials for literacy; there are also no audio-visual materials that would enable this language to be learned as a spoken language. We therefore place Gochang in the lowest possible level in the scale for this criterion - "no orthography is available to the community." As with the response to new domains, this inactivity in the literary domain is mirrored by all of China's invisible languages, as well as most of the smaller, formally recognized minority languages, representing a significant shortcoming in state-led language management. ${ }^{82}$

Government and institutional language attitudes and policies, including official status and use

The UNESCO guidelines for this criterion refer to the dominant population's treatment of non-dominant language groups, with the clarification that the dominant population might be nationally or regionally dominant. This clarification is significant for Gochang, which is dominated by putonghua at the national level, Sichuan Chinese at the local level, and Tibetan within an ethnic framework. The UNESCO guidelines state that the linguistic ideologies of the dominant population "may inspire linguistic minorities to mobilize their populations toward the maintenance of their languages, or may force them to abandon them." 83 They also distinguish between policies that support, discourage, or prohibit the use of a minority language.

Regarding government attitudes and policies, we can begin by noting that the constitution of the PRC explicitly states that all minorities have the freedom to use and develop their language. ${ }^{84}$ This constitutional freedom is enacted through law via such measures as the Education Law of the People's Republic of China ${ }^{85}$ and the Regional Ethnic Autonomy Law of the People's Republic of China. ${ }^{86}$ Despite these robust provisions, serious shortcomings in implementation exist. ${ }^{87}$ Furthermore, the only language that is actually named in any of these legal mechanisms is putonghua, with its mandatory use being enshrined in the Law of the People's Republic of China on the Standard Spoken and Written Chinese Language. ${ }^{88}$ There is, otherwise, no register of officially recognized languages. Instead, legal texts refer to "the language of the area" or "the native language commonly adopted in a region." In theory, this absence of official designation for languages and the reliance on "local conditions" mean that small languages such as Gochang could be used in formal government institutions, such as schools, courts, hospitals and bureaucracies, at a local level. ${ }^{89}$ Hans-Christian Schnack refers to such flexibility at the local level as "spaces of discretion," where vague wording in policy can empower low-level leaders in ways that serve local linguistic interests. ${ }^{90}$ In practice, however, the vagueness in language policy typically means that a single language, usually a written standard, is chosen as the paradigmatic language for each of China's 55 minority ethnic groups and promoted in their ethnic autonomous regions. This ambiguity, and the default recourse to ethnic policy as language policy, has created China's "invisible" 
languages and their vulnerable situation. In the Tibetan case, this means that written Tibetan is the only minority language which all Tibetans, in practice, have the freedom to use and develop, regardless of whether they actually speak it as a mother tongue or not.

In the context of government policy, we classify Gochang as receiving "differentiated support," which signifies that the "dominant language is the sole official language, while non-dominant languages are neither recognized nor protected." In this respect, Gochang is not only in a similar predicament to the 26 "invisible" languages spoken by Tibetans, but to all of the languages in China that lack recognition: 243 of the 298 recognized in Ethnologue.

In addition to formal government attitudes and policies, it is also important to consider Gochang within its ethnic and cultural setting, that of Tibetan society. Although Gochang speakers are surrounded primarily by Han Chinese, they identify with their ascribed Tibetan identity. Administratively, Gochang speakers also live within a Tibetan autonomous prefecture. How they are perceived and treated by Tibetans therefore matters to Gochang speakers.

Tibetan attitudes towards Gochang speakers could be described as ambiguous at best. Other Tibetans typically regard Gochang speakers as Tibetan, and consider their language to be an aberrant Tibetan "dialect." The language is significantly stigmatized, being generally considered less pure and sophisticated than standard Tibetan, not only because of its unintelligibility with local Tibetic varieties but also because it is unwritten. While Tibetans in places such as Kangding typically refer to Gochang using neutral terms like yul skad (local speech) and Go thang skad (Gotang speech), they also use the decidedly pejorative logs skad, which might be translated as "non-standard speech" or "jargon," thus cementing an association between the language and a socially marginalized identity. Local Tibetans typically consider Gochang speakers to be Sinicized, an attribute with decidedly negative connotations. An equally problematic label is that Gochang speakers are hybrids, neither fully Tibetan nor Chinese, an opinion expressed to us, for example, by the monks who were holding Tibetan classes in the Guza monastery. These negative attitudes towards the language and its speakers are compounded by the poor image that Guza has locally as a violent, chaotic and dangerous boomtown.

It is unclear how these attitudes from the broader Tibetan community should be graded in the UNESCO framework. Here, we merely note that Gochang speakers, although not subject to explicit assimilatory pressures from the larger Tibetan population, are subject to negative attitudes. This situation seems to more broadly reflect the situation of all of Tibet's "invisible" languages, which are subject to attitudes in the wider Tibetan population that are, at best, ambivalent, and at worse deeply pejorative. Among "invisible" languages more broadly in China, we expect similarly ambivalent attitudes among their titular ethnic population to prevail, although this appears to be mollified somewhat in the few cases where "invisible" languages are codified in writing. ${ }^{91}$

Community members' attitudes towards their own language 
The authors of the UNESCO guidelines note that "a positive attitude is critical for the long-term stability of a language," 92 an assertion that is supported by research on the relationship between linguistic attitudes and language endangerment, maintenance and revitalization. ${ }^{93}$

Song's survey of 95 Gochang-speakers under the age of 30 found that their attitudes were mostly negative. ${ }^{94}$ Respondents described Gochang as limited (shiyong shoudao xianzhi 使用受到限制), rustic ( $t u$ 土), useless for expressing one's thoughts (bu bianyu biaoda 不便于表达), and of limited value as a communicative medium (bu bianyu goutong 不便于沟通). In comparison, putonghua and Sichuan Chinese were described as more useful (youyong 有用) and elegant (timian 体面), with most prestige being attached to putonghua. ${ }^{95}$ Song also found that Gochang speakers were typically pessimistic about the fate of their language, with a majority of respondents saying that Gochang would either disappear or "merge" with Sichuan Chinese or putonghua in the future.

In addition to these negative attitudes recorded by Song, we can note a lack of explicit, positive discourses among Gochang speakers about their language; no one praises the language or advocates for its maintenance. Furthermore, Gochang speakers do not link their language with their Tibetan ethnicity. Although they do feel a sense of belonging and familiarity when encountering other Gochang speakers outside of Gotang, this shared identity is local rather than ethnic. This association between language and location is deeply significant in China, where ethnicity is both compulsory and public and has a legitimacy that subordinates localized identities and their related languages.

Given this situation, we optimistically rate community members' attitudes as a "two" at most - "Some members support language maintenance; others are indifferent or may even support language loss," 96 but more likely a "one" - "No one cares if the language is lost; all prefer to use a dominant language." "97 Negative and indifferent attitudes have also been reported as contributing to language endangerment elsewhere in China. ${ }^{98}$

\section{Urgency for documentation}

Language documentation aims to create a record of a language that is both comprehensive and representative, which can thus facilitate a wide range of future analyses by linguists, along with revitalization and other community-led efforts. ${ }^{99}$ The UNESCO guidelines claim that both the amount and the quality of existing documentation are important for language vitality insofar as documentation "helps members of the language community formulate specific tasks, and enables linguists to design research projects together with members of the language community." Although the guidelines emphasize the importance of written records, they also mention "transcribed, translated, and annotated audiovisual recordings of natural speech." 100

We rate the current level of documentation as "inadequate" - "only a few grammatical sketches, short word-lists, and fragmentary texts; audio and video recordings do not exist, are of unusable quality, or are completely un-annotated"; ${ }^{101}$ 
Yuan, Jin and Cao concur. ${ }^{102}$ There is a grammar of Gochang in English, ${ }^{103}$ as well as Sun's brief sketch and Song's monograph; ${ }^{104}$ however, all of these are descriptions of the language rather than documentation. Furthermore, we are unaware of any recordings that are available to the community. In terms of the broader context of language documentation in China, we note that although $\mathrm{Xu}$ provides a long list of language documentation projects in China, the amount of work currently being done is vastly disproportionate to the scale and urgency of the task. ${ }^{105}$

\section{Conclusion}

We consider that within the UNESCO language vitality framework, Gochang should be classified as "definitely endangered," a result supported by previous research. ${ }^{106}$ Looking through the nine criteria, we see the following. Intergenerational transmission has been declining and appears to have largely ceased within the last five years. The language has a relatively small number of speakers, who constitute a small minority on a number of levels: locally, ethnically, and nationally. Since 1949, multilingual parity between Tibetan and Gochang has been replaced by inegalitarian bilingualism in which new domains have proliferated and been occupied by Chinese. Gochang is not written or taught in schools, and very limited documentation exists. Neither government policies nor attitudes of mainstream Tibetan society support the language. Meanwhile, speakers of the language are, for the most part, indifferent to its fate. Gochang is therefore endangered primarily owing to a combination of demographic minoritization through urbanization and immigration, with sociopolitical minoritization through the language's exclusion from new domains.

Typesetter: please insert Figure 5 about here, with the following title Figure 5: Visualization of the Vitality of Gochang within UNESCO's Language Vitality and Endangerment Framework

What does Gochang tell us about linguistic diversity in western Sichuan and among Tibet's invisible languages more generally? Probably the most important dynamic described here is the shift from stable, Tibetan-Gochang diglossia, to unstable, Chinese-dominated inegalitarian bilingualism, leading to language shift. Many of the minority languages spoken by Tibetans are likely to be in a similar situation. A second important aspect is the impact of urbanization on Gochang, essentially minoritizing the language in its traditional homeland and resulting in a rapid language shift. With urbanization increasing across Tibet, many of the region's minority languages are likely facing a similar fate. These languages are also likely to be in a similar context to Gochang in being poorly documented, unwritten, and subject to assimilatory government policies and negative social attitudes from mainstream Tibetan society. Future studies of the vitality of Tibet's minority languages could therefore adapt the UNESCO framework to give less attention to criteria which are stable across languages, (for example, on literacy and documentation), and give more attention to other criteria by expanding them for local salience, as we have done here - for example, by recognizing the need to look at both formal state policy and the informal policies of mainstream Tibetan society. 
Finally, what can Gochang tell us about language endangerment in China more broadly? To what extent can it help us to understand why half of China's languages are currently endangered? Like many languages in China, Gochang faces two primary challenges. The first is its disembedding from a restricted local context and its re-embedding into a national one. This disrupts the relatively stable pattern of multilingualism that pertained in Gotang until recently, and was similar to the many stable multilingualisms which existed throughout China until recently. The second is the way in which the language has become endangered primarily through exclusion. The proliferation of new domains has been state-driven, a result of simultaneous modernization and state-building. The state's failure to include languages like Gochang in new domains is primarily a result of their invisibility - their lack of formal recognition by the state owing to the use of ethnic policy as a default language planning tool. This categorical exclusion results in the erasure of "invisible" languages from planning and policy, leading to their exclusion from institutions built by the state, thus bringing about their endangerment. Such languages face an entirely different predicament from those which are formally associated with a recognized minzu, as these languages are both re-embedded within and reproduced by state institutions.

At present, it seems that two changes in policy and practice could alter this trend. One would involve a process of formal language recognition, as distinct from ethnic recognition, in order to provide a framework for the inclusion of multiple languages for each of China's 56 ethnic groups in order to counteract the tendency to employ ethnic policy as default language policy. A second change might be that local governments could take advantage of the present lack of such a register, and the vague wording of language policy and law, to improvise informal processes of recognition that allow "invisible" languages to be included into local institutions such as education, media and government. If neither of these changes takes place, we should expect to see a deepening of China's language endangerment crisis, with an increasing endangerment and probably loss of more languages in the future. The broader social consequences for China of this ongoing, deepening crisis remain to be seen.

\section{Acknowledgement}

Gerald Roche's research for this article was funded by the Australian Research Council, under the auspices of a Discovery Early Career Research Award project entitled "Ethnicity and assimilation in China: the Case of the Monguor in Tibet" (DE150100388).

\section{Biographical notes}

Gerald Roche is an ARC Discovery Early Career Research Fellow at the University of Melbourne's Asia Institute. His most recent publications have appeared in Modern Asian Studies, The International Journal of the Sociology of Language, and Asian Ethnicity. 
Yudru Tsomu is currently associate professor at the Center for Tibetan Studies of Sichuan University. She received her PhD from Harvard University and was a postdoctoral fellow at Stanford University.

摘要：中国现正面临着语言濒危的危机，其一半以上的语言的使用者人数正在 减少。语言消亡和语言转变的动态是复杂的。一方面作为中国国家标准语言的 普通话正在产生广泛地影响, 而汉语的一些 “方言” 也正在取代另一些。另一 方面，一些少数民族语言的发展也是以牺牲其它少数民族语言为代价的，同时 受汉语方言和少数民族语言影响的带有地方口音的普通话也出现了。在本文 中, 我们以川西地区约 10,000 人使用的贵琼语为个案进行研究, 从而使我们进 一步了解中国语言的濒危现象。我们将贵琼语描述为一个 “隐形” 语言, 即它 是一种被国家的民族和语言政策忽略的语言, 因此, 它更容易受到由国家发展 项目而引起的社会变革的影响。我们通过运用联合国教科文组织制定的有关语 言活力和语言濒危的框架来评估贵琼语的濒危程度，并得出了该语言是 “绝对 处于濒危状态” 这一结论。我们将贵琼语与中国的其它的 “隐形” 语言进行比 较, 结果显示它们中的大多数都处于相似的困境。这意味着除非这些语言得到 国家的正式承认，或当地政府利用政策框架中的模棱两可之处来支持这些语 言, 否则中国语言的濒危危机很可能会继续。在目前我们还不清楚在中国持续 的、不断加深的语言濒危危机对社会有什么影响。

关键词：西藏，中国，语言濒危，语言政策

\section{References}

Austin, Peter. 2010. "Current issues in language documentation.” Language Documentation and Description 7, 12-33. http://www.elpublishing.org/PID/080.

Austin, Peter K., and Julia Sallabank (eds.). 2011. The Cambridge Handbook of Endangered Languages. Cambridge: Cambridge University Press.

Austin, Peter K., and Julia Sallabank (eds.). 2014. Endangered Languages: Ideologies and Beliefs in Language Documentation and Revitalization. London: British Academy.

Balogh, Mátyás. 2017. "Henan Oirat: a shrinking pool of unique linguistic features." The International Journal of the Sociology of Language 245, 37-62.

Bkra shis bzang po. 2012. "May all good things gather here: life, religion, and marriage in a Minyag Tibetan village." Asian Highlands Perspectives 14, 1369.

Bradley, David. 2002. "Language attitudes: the key factor in language maintenance." In David Bradley and Maya Bradley (eds.), Language Endangerment and Language Maintenance. London: RoutledgeCurzon, 1-10.

Bradley, David. 2005a. "Introduction: Language policy and language endangerment in China." International Journal of the Sociology of Language 173, 1-21.

Bradley, David. 2005b. "Sanie and language loss in China." International Journal of the Sociology of Language 173, 159-176. 
Bradley, David. 2015, a. "Review: A Grammar of Guiqiong: A Language of Sichuan by Jiang Li." Anthropological Linguistics. 57(4), 456-459.

Bradley, David. 2015, b. "Vitality of minority languages." In Rint Sybesma (ed.), Encyclopedia of Chinese Language and Linguistics. Leiden: Brill, http://dx.doi.org/10.1163/2210-7363_ecll_COM_00000443

Brassett, Philip, and Cecilia Brassett. 2005. "Diachronic and synchronic overview of the Tujia language of central south China." International Journal of the Sociology of Language 173, 75-97.

Chamberlain, Bradford Lynn. 2008. "Script selection for Tibetan-related languages in multiscriptal environments." International Journal of the Sociology of Language 192, 117-131.

Chirkova, Katia. 2008. Essential characteristics of Lizu, a Qiangic language of Western Sichuan. Workshop on Tibeto-Burman Languages of Sichuan, November 21-24, 2008, https://hal.archives-ouvertes.fr/hal00358909/document.

Chirkova, Katia. 2014. "The Duoxu language and the Ersu-Lizu-Duoxu relationship." Linguistics of the Tibeto-Burman Area 37(1), 104-146.

Chirkova, Katia, and Yiya Chen. 2013. "Xumi, part 1. Lower Xumi, the variety of the lower and middle reaches of the Shuiluo River." Journal of the International Phonetic Association 43(3), 363-379

Chirkova, Katia, Yiya Chen and Tanja Kocjančič Antolík. 2013. "Xumi, part 2: Upper Xumi, the variety of the upper reaches of the Shuiluo River." Journal of the International Phonetic Association 43(3), 381-396.

Dawa, Drolma, and Hiroyuki Suzuki. 2015. "Preliminary report of the linguistic area of Darmdo Minyag with a geolinguistic description of 'sun'." Studies in Asian Geolinguistics 1, 72-78.

de Varennes, Fernand. 2012. "Language rights and Tibetans in China: a look at international law." In Kunsang Gya, Andrea Snavely and Elliot Sperling (eds.), Minority Languages in Today's Global Society. New York: Trace Foundation, 39-61.

Ding, Picus Sizhi. 2014. A Grammar of Prinmi. Brill: Leiden.

Ding, Shiqing, and Desheng Meng. 2009. "Shaoshu minzu yuyan yu wenhua yanjiu liushi nian: huigu fansi zhanwang" (Sixty years' research on minority languages and culture: review, reflection and prospects). Zhongnan minzu daxue xuebao 29(6), 66-70.

Dorian, Nancy. 1981. Language Death: The Life Cycle of a Scottish Gaelic Dialect. Philadelphia: University of Pennsylvania Press.

Duchêne, Alexandre, and Monica Heller. 2008. Discourses of Endangerment. London: Continuum.

Edgar, James Huston. 1932. English-Giarung Vocabulary. Supplement to Volume V, Journal of the West China Border Research Society. Chengdu: The HarvardYenching Committee of the West China Union University.

Ekvall, Robert. 1964. Religious Observances in Tibet: Patterns and Function. Chicago: University of Chicago Press. 
Enwall, Joakim. 2012. "Conflicting tendencies in the influence of Putonghua on Hmu (Black Miao): orthography versus changing speech habits." The International Journal of the Sociology of Language 215, 125-139.

Ferguson, Charles. 1959. "Diglossia." Word: Journal of the International Linguistic Association 15(2), 232-251.

Fischer, Andrew. 2013. The Disempowered Development of Tibet in China: A Study in the Economics of Marginalization. New York: Lexington.

Fishman, Joshua. 1991. Reversing Language Shift: Theoretical and Empirical Foundations of Assistance to Threatened Languages. New York: Multilingual Matters.

Fried, Robert. 2010. “A Grammar of Bao'an Tu, a Mongolic language of northwest China." PhD diss., University of Buffalo, State University of New York.

$\mathrm{Fu}$, Maoji. 1984. "Jianguo sanshi wunian lai minzu yuyan keyan gongzuo de fazhan" (The development of the research on languages of ethnic minorities for 35 years since the establishment of the People's Republic of China). Minzu yuwen $5,1-8$.

G.yu lha. 2012. "Warming your hands with moonlight: Lavrung Tibetan oral traditions and culture." Asian Highlands Perspectives 13, 1-284, https://www.repository.cam.ac.uk/handle/1810/241079.

Gal, Susan. 1972. Language Shift: Social Determinants of Linguistic Change in Bilingual Austria. New York: Academic Press.

Gao, Katie. 2015. "Assessing the linguistic vitality of Miqie: an endangered Ngwi (Loloish) language of Yunnan, China." Language Documentation and Conservation 9, 164-191.

Gates, Jesse. 2014. Situ in Situ: Towards a Dialectology of Jiāróng (rGyalrong). Munich: Lincom Europa. - there is no cite for this: add cite or delete ref?

Gong, Qunhu. 2007. Zhabayu Yanjiu (A study of the Zhaba Language). Beijing: Minzu chubanshe.

Gong, Xun. 2013. "The personal agreement system of Zbu Rgyalrong (Ngyaltsu variety)." Transactions of the Philological Society 112(1), 44-60. DOI: http://dx.doi.org/10.1111/1467-968X.12007.

Grenoble, Lenore, and Lindsay Whaley (eds.). 1998. Endangered Languages: Language Loss and Community Response. Cambridge: Cambridge University Press.

Gutzlaff, Ch. 1850. "Tibet and Sefan.” Journal of the Royal Geographical Society of London 20, 191-227.

Himmelmann, Nikolaus. 1998. "Documentary and descriptive linguistics." Linguistics 36, 161-195.

Hodgson, Brian. 1853. "Sifan and Horsok vocabularies." Journal of the Asiatic Society of Bengal 22, 121-151.

Huang, Bufan. 1992. Zangmin yuzu yuyan cihui (Tibeto-Burman Languages and Vocabulary). Beijing: Central University for Nationalities Press.

Huang, Chenglong, Yunbing Li and Feng Wang. 2011. "Jilu yuyanxue: yimen xinxing jiaocha xueke" (Documentary linguistics: a newly emergent interdisciplinary subject). Yuyan kexue 3, 259-268. 
Huang, Xing. 1996. Zhongguo shaoshu minzu yuyan huoli yanjiu (A Study of the Vitality of Minority Languages of China). Beijing: Minzu chubanshe.

Hyslop, Gwendolyn. 2014. "Waves across the Himalayas: on the typological characteristics and history of the Bodic subfamily." Language and Linguistics Compass 8(6), 243-270.

Jacques, Guillaume (Xiang Bolin). 2008. Jiarongyu yanjiu (A Study of the Jiarong Language). Beijing: Minzu chubanshe.

Jiang, Li. 2015. A Grammar of Guiqióng: A Language of Sichuan. Leiden: Brill. Jiang, Wuji. 2004[1938]. "Yutong suoying" (The epitome of Yutong [Gotang]). In Zhao Xinyu and Qin Heping (eds.), Kangqu zangzu shehui lishi diaocha ziliao jiyao (The Selected Historical Investigation Materials of Tibetan Society in the Kham Region). Chengdu: Sichuan minzu chubanshe and Sichuan chuban jituan.

Jin, Suizi. 1998. "Kangding xian Yutong qu Guiqiong ren de zongjiao xisu (The religious customs of the Guiqiong people in Yutong township, Kangding county). Zongjiaoxue yanjiu 3, 82-87.

Krauss, Michael. 1992. “The world's languages in crisis.” Language 68(1), 4-10. Laufer, Berthold. 1916. "Loan-words in Tibetan." T'oung Pao 17, 403-552.

Lewis, M. Paul, Gary F. Simons and Charles D. Fennig (eds.). 2015. Ethnologue: Languages of the World (18th ed.). Dallas: SIL International. http://www.ethnologue.com.

Li, Fengxiang. 2005. "Contact, attrition, and structural shift: evidence from Oroqen." International Journal of the Sociology of Language 173, 55-74.

Li, Na. 2016. "Xibu minzu diqu tese xinxing chengzhenhua moshi yanjiu - jiyu Ganzi zangzu zizhizhou Kangding shi Guza zhen de diaoyan" (A study of the distinctive new urbanization model in minority areas in western China - an investigation of Guza town in Kangding, Ganzi Tibetan Autonomous Prefecture). Jinrong jingji 4, 26-28.

Libu, Lakhi, Brook Hefright and Kevin Stuart. 2007. "The Namuyi: linguistic and cultural features." Asian Folklore Studies 66, 233-253.

Limusishiden and Keith Dede. 2012. "The Mongghul experience: consequences of language policy shortcomings." International Journal of the Sociology of Language 215, 101-124.

Liu, Guangkun. 1998. Mawo Qiangyu yanjiu (A Study of the Mawo Qiang language). Chengdu: Sichuan minzu chubanshe.

Liu, Huiqiang, and Yunchuan Shang. 2006. "Zhengjiu Qiang yuzhi binwei yuyan Ersu yu, Namuyi yu, Guiqiong yu, Zhaba yu ziliao jilu he baocun" (Saving the endangered languages of the Qiangic language branch: recording materials and preservation of Ersu, Namuyi, Guiqiong and Zhaba Lanugage). Xinan minzu daxue xuebao 27(12), 11-12.

Liu, Jinrong, and Qi Zhang. 2015. "An analysis of the current status and language endangerment of the Kucong language at Shuitang township in Xinping county." Linguistics of the Tibeto-Burman Area 38(2), 215-224.

Loh, Jonathan, and David Harmon. 2014. "Biocultural diversity: threatened species, endangered languages.” WWF Netherlands, 
http://d2ouvy59p0dg6k.cloudfront.net/downloads/bioculturalreportjune2014.p df.

McConvell, Patrick. 1991. "Understanding language shift: a step towards language maintenance.” In Suzanne Romaine (ed.), Language in Australia. Cambridge: Cambridge University Press, 143-156.

Miao, Ruiqin, and Jiaxuan Li. 2006. "Urban migration and functional bilingualism in Guangdong province, China." Journal of Asian Pacific Communication 16(2), 237-257.

Moseley, Christopher (ed.). 2010. Atlas of the World's Languages in Danger (3rd ed.). Paris: UNESCO. http://www.unesco.org/languages-atlas/.

Nettle, Daniel, and Suzanne Romaine. 2000. Vanishing Voices: The Extinction of the World's Languages. Oxford: Oxford University Press.

Nie, Hongyin, and Hongkai Sun. 2010. Xifan Yiyu jiaolu ji huibian (Collated and Collected Vocabularies of Xifan Yiyu). Beijing: Shehui kexue wenxian chubanshe.

Nishida, Fuminobu. 2005. "A sociolinguistic study of the Namuyi language in Sichuan, China.” Reitaku Journal of Interdisciplinary Studies 13(1), 13-21.

Nishida, Fuminobu. 2008. "Tyuyugo no on-in taikei" (Phonology of the Choyu language). Tyuugoku kenkyuu 16, 77-85.

Roche, Gerald. 2014. "The vitality of Tibet's minority languages in the twenty-first century: preliminary remarks." Multiethnica 35, 24-30.

Roche, Gerald. 2017. "The transformation of Tibet's language ecology in the 21st century." The International Journal of the Sociology of Language 245, 1-35.

Roche, Gerald, and Lcag mo tshe ring. 2013. "Notes on the maintenance of diversity in Amdo: language use in Gnyan thog village annual rituals." Studia Orientalia 113, 165-179.

Roche, Gerald, and Hiroyuki Suzuki. Forthcoming. "Tibet's minority languages: diversity and endangerment." Modern Asian Studies.

Rohsenow, John. 2007. "Fifty years of script and written language reform in the PRC: the genesis of the language law of 2001." In Minglang Zhou and Hongkai Sun (eds.), Language Policy in the People's Republic of China: Theory and Practice since 1949. Boston: Kluwer Academic Publishers, 21-44.

Rosthorn, A. von. 1897. "Vocabular fragmente Ose-Tibetische Dialekts" (Vocabulary fragments of East Tibetan dialects). Zeitschrift der Deutschen Morgenlandischen Gesellschaft 51, 524-531.

Ryavec, Karl. 2015. A Historical Atlas of Tibet. Chicago: University of Chicago Press.

Sallabank, Julia. 2013. Attitudes to Endangered Languages: Identities and Policies. Cambridge: Cambridge University Press.

SBCESS (Sichuan Branch of the Chinese Ethnic Studies Society) 1987. Minjian wenyi ziliao: Yang Qijinchu gushi ji (Materials of Folk Literature and Art: The Collection of Stories Told by Yang Qijiancuo). No publisher.

Schnack, Hans-Christian. 2016. "Testing the spaces of discretion: school personnel as implementers of minority-language policy in China." Journal of Current Chinese Affairs 45(1), 43-74. 
Song, Lingli. 2006. "Chuanxi minzu zoulang binwei yuyan gaikuang” (A general account of the endangered languages in the ethnic corridor of western Sichuan). Jinan xuebao 5, 137-141.

Song, Lingli. 2011. Guiqiong yu yanjiu (A Study of the Guiqiong Language). Beijing: Minzu chubanshe.

Song, Lingli. 2012. "Guiqiong yu yuyan shengtai kaocha" (An investigation into the linguistic ecology of the Guiqiong language). Huaxi yuwen xuekan 7, 34-40.

Spolsky, Bernard. 2014. Language management in the People's Republic of China. Language 90(4), e165-e179.

Stanford, James, and Jonathan P. Evans. 2012. "The influence of Mandarin Chinese on minority languages in rural southwest China: a sociolinguistic study of tones in contact." The International Journal of the Sociology of Language $215,79-100$.

Stanford, James N., and J. Whaley. 2010. "The sustainability of languages." International Journal of Environmental, Cultural, Economic, and Social Sustainability 6(3), 111-121.

Stevenson, Paul Huston. 1932. "Notes on the human geography of the ChineseTibetan borderland." Geographical Review 22(4), 599-616.

Sun, Hongkai (Jackson Sun (trans.)). 1990. "Languages of the ethnic corridor in western Sichuan." Linguistics of the Tibeto-Burman Area 13(1), 1-31.

Sun, Hongkai. 1983. "Chuanxi minzu zoulang diqu de yuyan" (The languages of the "ethnic corridor" region of western Sichuan). Xinan minzu yanjiu 1, 429-454.

Sun, Hongkai. 2005. "The Anong language: studies of a language in decline." International Journal of the Sociology of Language 173, 143-157.

Sun, Hongkai, Katia Chirkova (Qi Kajia) and Liu Guangkun. 2008. Baimayu yanjiu (A Study of the Baima language). Beijing: Minzu chubanshe.

Sun, Jackson. 2003. "Caodeng rGyalrong." In Graham Thurgood and Randy LaPolla (eds.), Sino-Tibetan Languages. London: Routledge, 490-502.

Suzuki, Hiroyuki. 2012. "Ergative marking in Nyagrong-Minyag (Xinlong, Sichuan)." Linguistics of the Tibeto-Burman Area 35(1), 35-48.

Teichman, Eric. 1922. Travels of a Consular Officer in Eastern Tibet: Together with a History of the Relations between China, Tibet and India. Cambridge: The University Press.

The Geographic Journal. 1908. "The tribes of north-western Se-Chuan.” 32(6), 594597.

Thomason, Sarah. 2015. Endangered Languages: An Introduction. Cambridge: Cambridge University Press.

Tournadre, Nicolas. 2014. "The Tibetic languages and their classification." In Thomas Owen-Smith and Nathan W. Hill (eds.), Trans-Himalayan Linguistics: Historical and Descriptive Linguistics of the Himalayan Area. Berlin: Walter de Gruyter, 105-129

Tshe ring skyid. 2015a. "An introduction to Rgya tshang ma, a Monguor (Tu) village in Reb gong (Tongren)." Asian Highlands Perspectives 37, 276-300. 
Tshe ring skyid. 2015b. "Rka gsar, a Monguor (Tu) village in Reb gong (Tongren): communal rituals and everyday life." Asian Highlands Perspectives 37, 251275.

Tsung, Linda. 2012. "Language and power: Tuanjie hua, an Yi-Han mixed language." The International Journal of the Sociology of Language 215, 63-77.

Tunzhi. 2017. "Language vitality and glottonyms in the ethnic corridor: the Rta'u language." The International Journal of the Sociology of Language 245, 147168.

Uchida, Emi, Jintao Xu and Scott Rozelle. 2005. "Grain for green: cost-effectiveness and sustainability of China's conservation set-aside program." Land Economics 81, 247-264.

UNESCO (United Nations Educational, Scientific, and Cultural Organization). 2003. "Language vitality and endangerment." Document submitted to the International Expert Meeting on UNESCO Programme Safeguarding of Endangered Language, Paris, 10-12 March, http://www.unesco.org/culture/ich/doc/src/00120-EN.pdf.

UNESCO. 2011. 'UNESCO's Language Vitality and Endangerment methodological guideline: review of application and feedback since 2003." Background paper, http://www.unesco.org/new/fileadmin/MULTIMEDIA/HQ/CI/CI/pdf/unesco language_vitaly_and_endangerment_methodological_guideline.pdf.

van Way, John, and Bkrashis Bzangpo. 2015. "Nyagrong Minyag: prestige and maintenance of a traditional language on the Tibetan periphery." Linguistics of the Tibeto-Burman Area 38(2), 245-255.

Wen, Maotao. 2014. "The Creation of the Qiang Ethnicity, its Relation to the Rme People, and the Preservation of the Rme language." MA diss., Duke University.

Wolfenden, Stuart. 1936. "Notes on the Jyarung dialect of Eastern Tibet." T'oung Pao 32(2/3), 167-204.

$\mathrm{Wu}, \mathrm{Da} .2015$. "Three tongues and two identities: a case study of Ersu ethnic identities in Sichuan, China." Cultural Diversity in China 1(1), 44-67.

Xiong, Shunqing. 2015. "A survey of the current situation of Achang." Linguistics of the Tibeto-Burman Area 38(2), 207-214.

Xu, Shixuan. 2013. "Language endangerment." In Li Yuming and Li Wei (eds.), The Language Situation in China Vol. 1. Berlin: De Gruyter, 261-270.

$\mathrm{Xu}$, Shixuan. 2005. "Survey of the current situation of Laomian and Laopin in China." International Journal of the Sociology of Language 173, 99-115.

Yeh, Emily. 2009. "Greening western China: a critical view." Geoforum 20, 884-894.

Yeh, Emily. 2013. Taming Tibet: Landscape Transformation and the Gift of Chinese Development.

Yixi Weisa Acuo. 2004. Daohua yanjiu (A Study of Daohua). Beijing: Minzu chubanshe.

Yu, Defen. 2015. "The impact of urbanization and Han Chinese migration on the endangerment of languages and cultures in China: a case study on Samatao of Kunming." Linguistics of the Tibeto-Burman Area 38(2), 161-173. 
Yuan, Li, Ming Jin and Rong Cao. 2015. "Zuqun jiechu zhong ruoshi yuyan de fazhan - jiyu Guiqiong yu binwei xing de sikao" (The development of weak languages amid ethnic contacts, based on the reflection on the endangerment of Guiqiong language). Aba shifan gaodeng zhuanke xиexiao xиebao 32(4), 38-41.

Yudru Tsomu. 2009. "Political and territorial survival in the Sino-Tibetan borderland: a case study of the 1Cags-laKingdom during the Qing Dynasty." In Wim van Spengen and Lama Jabb (eds.), Studies in the History of Eastern Tibet. PIATS 2006. Tibetan Studies: Proceedings of the Eleventh Seminar of the International Association for Tibetan Studies, Koningswinter. Halle (Saale): International Institute for Tibetan and Buddhist Studies, 55-96.

Yudru Tsomu. 2012. "Taming the Khampas: the Republican construction of eastern Tibet." Modern China 39(3), 319-344.

Yudru Tsomu. 2015. The Rise of Gönpo Namgyel in Khams: The Blind Warrior of Nyarong. New York: Lexington Books.

Zeisler, Bettina. 2004. Relative Tense and Aspectual Values in Tibetan Languages: A Comparative Study. Berlin: Mouton de Gruyter.

Zhou, Minglang. 2004. "Minority language policy in China: equality in theory and inequality in practice." In Minglang Zhou and Hongkai Sun (eds.), Language Policy in the People's Republic of China: Theory and Practice since 1949. Boston: Kluwer Academic Publishers, 71-96.

Zhou, Minglang. 2006. "Theorizing language contact, spread, and variation in status planning: a case study of modern standard Chinese." Journal of Asian Pacific Communication 16(2), 159-174.

Zhou, Minglang. 2012. "The contact between Putonghua (modern standard Chinese) and minority languages in China." International Journal of the Sociology of Language 215, 1-17.

Zhou, Tingsheng, and Suhua Hu. 2015. "Vitality and endangerment of the Lalo language: a case study in Xiaowan area and a comparison of the domains of language use between Nuosu Yi areas and Lalo Yi areas." Linguistics of the Tibeto-Burman Area 38(2), 225-244.

\footnotetext{
${ }^{1}$ Moseley 2010; Lewis, Simons and Fennig 2015; Xu 2013; Liu, Jinrong, and Zhang 2015.

${ }^{2}$ Loh and Harmon 2014.

${ }^{3}$ Xiong 2015; Liu, Jinrong, and Zhang 2015; Zhou, Tingsheng, and Hu 2015; Yu 2015; Brassett and Brassett 2005; Li, Fengxiang 2005; Sun 2005.

${ }^{4}$ Zhou, Minglang 2006.

${ }^{5} \mathrm{Xu} 2013$.

${ }^{6}$ Zhou, Minglang 2012; 2006; Miao and Li 2006; Stanford and Evans 2012.

${ }^{7}$ Bradley 2005a, 11.

${ }^{8}$ The Tibetan areas of China include those administrative units which are officially recognized as Tibetan autonomous areas (the Tibet Autonomous Region; Haixi, Haibei, Yushu, Guoluo, Hainan and Huangnan prefectures in Qinghai province; Gannan prefecture and Tianzhu county in Gansu province; Aba and Ganzi prefectures and Muli county in Sichuan province; and Diqing prefecture in Yunnan
} 
province), as well as several counties adjacent to these areas, where Tibetans live in significant numbers. For brevity's sake, we refer to this area as Tibet.

${ }^{9}$ Tournadre 2014, 107. Linguists in and outside of China have typically considered Tibetan to be a single language with three "dialects": Amdo, Kham and U-Tsang. This largely reflects the predominant view among Tibetans as well.

${ }^{10}$ Zeisler 2004 refers to "Tibetan" language, Hyslop 2014 to the "Bodish" languages, and Tournadre 2014 to the "Tibetic" languages. Tournadre (2014) lists 15 Tibetic languages in China: Ü-Tsang, Khams, Hor, Amdo, Kyirong, Khalong, Zhongu, gSerpa, Khöpokhok, Palkyi/Chos-rje, Sharkhok, Thewo, Chone, Drugchu and Baima. Ryavec 2015 provides a map showing the distribution of these languages.

${ }^{11}$ Roche and Suzuki forthcoming.

${ }^{12}$ Roche 2014; 2017.

${ }^{13}$ Roche 2014, 29.

${ }^{14}$ Roche and Suzuki forthcoming; Lewis, Simons and Fennig 2015.

${ }^{15}$ Balogh 2017; Tunzhi 2017.

${ }^{16}$ Van Way and Bkrashis Bzangpo 2015, 255; Fried 2010. Manegacha is known to linguists as

Bao'an/Bonan or Tongren Tu; Manegacha is the name used by the speakers.

${ }^{17}$ Chirkova 2008, 6.

${ }^{18}$ Chirkova 2014, 104.

${ }^{19}$ Nishida 2005, 15. Libu Lakhi, Hefright and Stuart 2007 also describe the language as endangered.

${ }^{20}$ Jiang Li (2015) gives the IPA for this as $g^{33} \mathrm{t}^{h_{i}} \mathrm{j}^{55}$ and gu $\mathrm{gu}^{33} \mathrm{~d} \quad \mathrm{i} \mathrm{j}^{21}$; Hiroyuki Suzuki (in a personal communication) provides ${ }^{\mathrm{n}} \mathrm{go}^{33} \mathrm{t}{ }^{\mathrm{h}} \sim 55$ and gwi ${ }^{55} \mathrm{t}^{\mathrm{h} \sim 33}$ based on two different informants.

${ }^{21}$ Rgyal rong Rgyal mo rngul chu.

${ }^{22}$ Dar tse mdo.

${ }^{23}$ Dkar mdzes, Ganzi.

24 'Go thang/Mgu thang/'Go thom, Yutong.

${ }^{25}$ rgyal po; for more on the Tibetan kingdoms and other polities of western Sichuan, see Yudru Tsomu $2009,2015$.

${ }^{26}$ Yeh 2013; Fischer 2013.

${ }^{27}$ Krauss 1992; Austin and Sallabank 2011; Thomason 2015; for a critical perspectives see Duchêne and Heller 2008.

${ }^{28}$ Bradley 2015b; Huang, Xing 1996; Xu 2013.

${ }^{29}$ Stanford and Whaley 2010.

${ }^{30}$ UNESCO 2003, 2011.

${ }^{31}$ Twenty-two out of the total 26. Among these 22, only the Baima language, which is also spoken in southern Gansu, is found outside of Sichuan.

${ }^{32}$ Rnga ba, Aba.

${ }^{33}$ Nie and Sun 2010.

${ }^{34}$ Hodgson 1853; Rosthorn 1897; Laufer 1916; Edgar 1932; Wofenden 1936.

${ }^{35}$ Gutzlaff 1850; The Geographic Journal 1908; Teichman 1922; Stevenson 1932; Ekvall 1964.

${ }^{36}$ Yudru Tsomu 2012.

${ }^{37}$ Jiang, Wuji 2004[1938].

${ }^{38} \mathrm{Fu} 1984$.

${ }^{39}$ Ding and Meng 2009.

${ }^{40}$ Sun 1983; 1990.

${ }^{41}$ Wu 2015; van Way and Bkrashis Bzangpo 2015; Song 2012; Tunzhi 2017.

${ }^{42}$ Fishman 1991.

${ }^{43}$ Jiang, Li 2015; Song 2006; Yuan, Jin and Cao 2015.

${ }^{44}$ UNESCO 2003, 7.

${ }^{45}$ Zhou, Tingsheng, and $\mathrm{Hu} 2015$.

${ }^{46}$ Jiang, Li 2015.

${ }^{47}$ Ibid., 17.

${ }^{48}$ Sun 1983; Huang, Bufan 1992; Song 2012. 
${ }^{49}$ UNESCO 2003, 9.

${ }^{50} \mathrm{Li}, \mathrm{Na} 2016$, 27. Jiang, $\operatorname{Li}(2015,18)$ sites a population of 167,000 , a figure also found on the town's official website. Although this figure seems improbable, given that the official population of Kangding municipality is 130,142 , it may include the town's significant floating population, including students in the university and migrant workers, suggesting that less than a third of the town's population are local residents.

${ }^{51}$ Van Way and Bkrashis Bzangpo 2015 provide another case of dam construction and language endangerment in western Sichuan.

${ }^{52}$ Uchida, Xu and Rozelle 2005; Yeh 2009.

${ }^{53}$ Yuan, Jin and Cao 2015.

${ }^{54}$ Based on 2010 census figures, China's Tibetan population is approximately 6.2 million.

${ }_{56}^{55}$ Roche and Suzuki forthcoming.

${ }^{56}$ Gao 2015; Liu, Jinrong, and Zhang 2015; Yu 2015; Brassett and Brassett 2005; Tsung 2012.

${ }^{57}$ Fishman 1991, 44.

${ }^{58}$ For a critique of Fishman's domain model, see McConvell 1991.

${ }^{59}$ Jiang, Li 2015, 14.

${ }^{60}$ For examples of this, see Roche and Lcag mo tshe ring 2013; Tshe ring skyid 2015a; 2015b; G.yu lha 2012; Bkra shis bzang po 2012; Tunzhi 2017.

${ }^{61}$ For a collection of stories from the female bard Yang Qijincu (1898-1986), see SBCESS 1987.

${ }^{62} \mathrm{Jin} 1998$ provides details on the religious practices in Gotang.

${ }^{63}$ Jiang, Wuji 2004[1938].

${ }^{64}$ UNESCO 2003, 9.

${ }^{65}$ Bradley 2015a.

${ }^{66}$ Ferguson 1959, 245.

${ }^{67}$ Roche 2017.

${ }^{68}$ UNESCO 2003, 11.

${ }^{69}$ Nettle and Romaine 2000, 91.

${ }^{70}$ Gal 1972; Dorian 1981.

${ }^{71}$ McConvell 1991, 149.

${ }^{72}$ Including not only government administrative offices but also such government-run services as post offices, hospitals and medical clinics, schools, and some banks, in both Guza and the Gochangspeaking villages.

${ }^{73}$ Enwall 2012 describes a similar situation for Hmu-speaking Miao in Guizhou.

${ }^{74}$ There is no senior middle school in Guza, and so local students must go to Luding, Kangding or Mianyang if they continue past junior middle school.

${ }^{75}$ Jiang. Li 2015, 18. Tibetan is used at Sichuan Minzu College for Tibetan majors. Buddhist monks have started a programme to teach written Tibetan to students in nearby Guza town, but when we visited the monastery, only a handful of students were studying there.

${ }^{76}$ Although Sichuan Chinese is used occasionally on TV, there is no Sichuan Chinese dominant media available in Gotang.

${ }^{77}$ UNESCO 2003, 11.

${ }^{78}$ Zhou, Tingsheng, and Hu 2015; Xu 2005; Bradley 2005b.

${ }^{79}$ Limusishiden and Dede 2012; Stanford and Evans 2012.

${ }^{80}$ UNESCO 2003, 12.

${ }^{81}$ Grenoble and Whaley 1998, 34. For the complexities of using the Tibetan script to write languages other than Tibetan, see Chamberlain 2008. For an attempt to use the Tibetan script to write a Qiangic language, see Wen 2014.

${ }^{82}$ Spolsky 2014.

${ }^{83}$ UNESCO 2003, 12.

${ }^{84}$ For an English version of the constitution, see http://en.people.cn/constitution/constitution.html. Accessed 20 December 2017.

${ }^{85}$ An English version of the law can be accessed at http://www.china.org.cn/english/education/184669.htm. Accessed 20 December 2017. 
${ }^{86}$ For English and Chinese versions of the law, see http://www.cecc.gov/resources/legalprovisions/regional-ethnic-autonomy-law-of-the-peoples-republic-of-china-amended. Accessed 20 December 2017.

${ }^{87}$ de Varennes 2012; Zhou, Minglang 2004; Limusishiden and Dede 2012.

${ }^{88}$ Rohsenow 2007. For an English text of this law, see http://www.npc.gov.cn/englishnpc/Law/200712/11/content1383540.htm. Accessed 20 December 2017.

${ }^{89}$ Yuan, Jin and Cao 2015.

${ }^{90}$ Schnack 2016.

${ }^{91}$ Enwall 2012; Bradley 2005b.

${ }^{92}$ UNESCO 2003, 16.

${ }^{93}$ Bradley 2002; Sallabank 2013; Austin and Sallabank 2014.

${ }^{94}$ Song 2006.

${ }^{95}$ Song did not ask about attitudes to Tibetan.

${ }^{96}$ UNESCO 2003, 15.

${ }^{97}$ Ibid.

${ }^{98}$ Enwall 2012; Liu, Jinrong, and Zhang 2015; Sun 2005.

${ }^{99}$ Himmelmann 1998; Austin 2010; Huang, Chenglong, Li and Wang 2011.

${ }^{100}$ UNESCO 2003, 16.

${ }^{101}$ Ibid.

${ }^{102}$ Yuan, Jin and Cao 2015.

${ }^{103}$ Jiang, Li 2015.

${ }^{104}$ Sun 1983; 1990; Song 2011.

${ }^{105} \mathrm{Xu} 2013$.

${ }^{106}$ Song 2006; Yuan, Jin and Cao 2015; Liu, Huiqiang, and Shang 2006. 